\title{
Pengaruh Electronic Service Quality dan Electronic Word of Mouth terhadap Keputusan Pembelian Kamar: Studi Kasus Aston Denpasar Hotel and Convention Center
}

\author{
Maureen Audria1, I Nyoman Sudiksa², Ida Ayu Kalpikawati*3 \\ 1,2,3Program Studi Bisnis Hospitaliti, Politeknik Pariwisata Bali, \\ Jalan Dharmawangsa, Kampial, Nusa Dua, Bali, Indonesia. \\ 19maureenaudria@gmail.com, 2nsudiksa@gmail.com,3*idakalpika@yahoo.com \\ *Corresponding author
}

\author{
\begin{tabular}{l|l|l} 
Received: Oktober, 2021 & Accepted: Oktober, 2021 & Published: Desember, 2021
\end{tabular}
}

\begin{abstract}
This study aimed to analyze the influence of Electronic Service Quality and Electronic Word of Mouth on Room Purchase Decisions at Aston Denpasar Hotel \& Convention Center. The data were collected by distributing online questionnaires with the help of the hotel to respondents who were guests who had stayed at Aston Denpasar Hotel \& Convention Center totaling 100 people. The data collected from the questionnaire were then analyzed using the classic assumption test, multiple linear regression analysis, $t$ test, $F$ test and coefficient of determination analysis. The results showed (1) electronic service quality had a positive and significant effect on room purchase decisions with a significance value of $0.011<0.1$ indicating that $H_{0} 1$ was rejected and $H_{a} 1$ was accepted (2) electronic word of mouth had an effect positive and significant impact on room purchase decisions with a significance value of $0.010<0.1$ indicating that $\mathrm{H}_{0} 2$ is rejected and $\mathrm{H}_{a} 2$ is accepted (3) electronic service quality and electronic word of mouth has a positive and significant effect on room purchase decisions with a significance value of 0,000 $<0.1$ indicate that $H_{0} 3$ is rejected and $H_{a} 3$ is accepted.
\end{abstract}

Keywords: electronic service quality, electronic word of mouth, purchasing decisions

\begin{abstract}
Abstrak
Penelitian ini bertujuan untuk menganalisis pengaruh electronic service quality dan electronic word of mouth terhadap keputusan pembelian kamar di Aston Denpasar Hotel \& Convention Center. Teknik pengumpulan data yang digunakan adalah dengan menyebar kuesioner online dengan bantuan pihak hotel kepada responden yang merupakan tamu yang pernah menginap di Aston Denpasar Hotel \& Convention Center sejumlah 100 orang. Data hasil pengumpulan kuesioner kemudian dianalisis dengan uji asumsi klasik, analisis regresi linear berganda, uji $t$, uji $F$ dan analisis koefisien determinasi. Hasil penelitian menunjukkan (1) electronic service quality berpengaruh positif dan signifikan terhadap keputusan pembelian kamar dengan nilai signifikansi 0,011 < 0,1 yang mengindikasikan bahwa $H_{0} 1$ ditolak dan $H_{a} 1$ diterima (2) electronic word of mouth berpengaruh positif dan signifikan terhadap keputusan pembelian kamar dengan nilai signifikansi 0,010 $<0,1$ yang
\end{abstract}


Pengaruh Electronic Service Quality dan Electronic Word of Mouth terhadap Keputusan Pembelian Kamar

Maureen Audria, I Nyoman Sudiksa, Ida Ayu Kalpikawati

mengindikasikan bahwa $\mathrm{H}_{0} 2$ ditolak dan $\mathrm{H}_{a} 2$ diterima (3) electronic service quality dan electronic word of mouth berpengaruh positif dan signifikan terhadap keputusan pembelian kamar dengan nilai signifikansi 0,000 < 0,1 mengindikasikan bahwa $\mathrm{H}_{0} 3$ ditolak dan $\mathrm{H}_{a} 3$ diterima

Kata kunci: electronic service quality, electronic word of mouth, keputusan pembelian

\section{PENDAHULUAN}

Era revolusi industri 4.0 yang ditandai dengan perkembangan digitalisasi telah terjadi di semua industri termasuk industri perhotelan. Menurut Kazandzhieva, dkk. (2017) saat ini turis menggunakan teknologi secara meluas dalam melakukan pemilihan tempat serta layanan terbaik sesuai dengan kebutuhan spesifik yang diinginkan. Setiap tamu dapat memiliki ekspektasi terhadap kondisi hotel tanpa terlebih dahulu mengunjungi atau melihat kondisi fisik hotel secara langsung. Informasi awal yang dimiliki tamu terkait dengan produk dan layanan hotel akan berpengaruh pada kemungkinan tamu dalam memutuskan pembelian produk hotel.

Perkembangan teknologi pada industri perhotelan memberikan pengaruh terhadap pemasaran yang dilakukan pihak hotel. Pemasaran tradisional telah beralih menjadi pemasaran digital dengan memanfaatkan internet. Menurut Desai (2019) pemasaran digital mencakup seluruh upaya pemasaran yang menggunakan perangkat elektronik atau internet. Pemasaran digital terdiri atas situs website, Search engine Optimization (SEO), Social Media Marketing, Content Marketing, Affiliate Marketing, Native Marketing, Marketing Automation, Pay-Per-Click, Email Marketing, Inbound Marketing dan PR online.

Pemanfaatan company website menjadi salah satu pemasaran digital yang popular dalam bisnis termasuk dalam industri perhotelan. Menurut Pandora Media, Inc (2017) company website adalah situs website yang dimiliki, dioperasikan dan diselenggarakan oleh perusahaan, anak perusahaan atau suatu perusahaan yang memiliki tugas untuk mengelola platform seperti situs website. Hotel harus memperhatikan kualitas situs website, karena sebagai media yang memberikan informasi hotel kepada tamu dalam pengambilan keputusan. Tamu memandang situs website sebagai kualitas layanan hotel secara elektronik (electronic service quality) sehingga desain, tampilan dan isi situs website harus dikelola dengan baik dan benar (Zhang dan Tang, 2006). Menurut Parasuraman, dkk. (2005) dalam Shared (2019), electronic-service quality merupakan penilaian pelanggan terhadap pelayanan yang disediakan melalui internet. Pada hal tersebut pelayanan melalui internet yang disediakan oleh pihak hotel berupa Website. Parasuraman, dkk (2005) dalam Shared (2019), menyatakan bahwa E-ServQual memiliki definisi yang luas yang mencakup seluruh fase dalam situs pelanggan dengan website. Menurut Swaid dan Wigand (2019), atribut E-ServQual terdiri atas 6 dimensi yaitu website usability, kualitas informasi, reliabilitas, responsif, jaminan dan personalisasi.

Selain electronic service quality, word of mouth (WOM) juga merupakan suatu alat promosi yang efektif karena pada umumnya disampaikan dari konsumen oleh konsumen dan untuk konsumen, sehingga konsumen yang puas dapat menjadi media iklan bagi perusahaan. Dengan perkembangan teknologi menyebabkan WOM beralih menjadi eWOM. Electronic word of mouth (e-WOM) sebagai salah satu pemasaran digital yang memberikan informasi aktual hotel dari tamu yang pernah menginap kepada tamu yang sedang melakukan pemilihan hotel. Menurut Kotler dan Keller (2008:6), saluran komunikasi personal dalam ucapan atau perkataan dari mulut ke mulut atau word of mouth (WOM) bisa menjadi metode promosi yang efektif karena pada umumnya disampaikan dari konsumen oleh konsumen dan untuk konsumen, sehingga konsumen yang puas dapat menjadi media iklan bagi perusahaan. Kemudian, menurut Jalilvand, dkk. (2011) electronic word of mouth mengacu pada penyataan positif atau negatif yang dibuat 
oleh konsumen potensial, aktual atau konsumen yang telah membeli tentang suatu produk atau perusahaan, yang tersedia untuk banyak orang atau lembaga melalui internet.

Aston Denpasar Hotel \& Convention Center merupakan hotel yang telah melakukan berbagai kegiatan promosi secara online dan offline. Promosi online yang diterapkan antara lain melalui electronic service quality (situs website), electronic word of mouth atau ulasan online dan sosial media. Promosi yang dilakukan secara offline adalah kegiatan sales call dan penyebaran flyer. Berbagai kegiatan promosi baik secara online maupun offline diharapkan dapat meningkatkan kinerja hotel, salah satunya berupa peningkatan jumlah kamar terjual. Pada Tabel 1 dapat dilihat data komparasi jumlah kamar terjual melalui promosi online dan offline sebagai berikut.

Berdasarkan Tabel 1 dapat dilihat bahwa selama periode tahun 2017-2019 jumlah kamar terjual melalui promosi offline masih lebih besar dibandingkan kamar terjual melalui promosi online. Terjadi peningkatan jumlah kamar terjual melalui promosi online, dan terjadi penurunan total kamar terjual melalui promosi offline. Hal ini menunjukkan bahwa tamu mulai beralih untuk memperoleh informasi hotel melalui pemasaran digital dibandingkan pemasaran tradisional. Terkait dengan kegiatan pemasaran digital, Aston Denpasar Hotel \& Convention Center memberikan perhatian yang sangat besar dan intensif pada promosi melalui electronic service quality dan electronic word of mouth. Perhatian besar dan intensif terhadap kedua promosi tersebut antara lain berbentuk; mengupayakan peningkatan kunjungan situs website, melakukan pendataan kunjungan situs website, melakukan pembaharuan secara rutin dan memberikan tanggapan terhadap ulasan online. Namun Aston Denpasar Hotel \& Convention Center belum melakukan pendataan secara khusus terkait dengan ulasan online yang diberikan oleh tamu.

Tabel 1: Penjualan Kamar Online \& Offline Aston Denpasar Hotel \& Convention Center 2017-2019 [Sumber: General Manager Report 2017-2019]

\begin{tabular}{cccc}
\hline Tahun & Kamar Terjual & Terjual Online & Terjual Offline \\
\hline 2017 & 55.076 & 19.827 & 35.249 \\
2018 & 52.542 & 20.491 & 32.051 \\
2019 & 50.606 & 20.748 & 29.858 \\
Total & 158.224 & 61.066 & 97.158 \\
\hline
\end{tabular}

Dalam rangka meningkatkan kualitas layanan melalui situs website (electronic service quality), hotel melakukan pembaharuan rutin. Pada Tabel 2 dapat dilihat data agenda pembaharuan rutin situs website Aston Denpasar Hotel \& Convention Center Tahun 2017-2019. Berdasarkan Tabel 2 dapat dilihat bahwa Aston Denpasar Hotel \& Convention Center melakukan pembaharuan secara rutin pada berbagai menu seperti harga kamar, foto terbaru dan menu informasi lain. Hal tersebut dilakukan pihak hotel agar pengunjung situs website hotel mendapatkan informasi terbaru terkait dengan hotel. Hal tersebut menunjukkan bahwa Aston Denpasar Hotel \& Convention Center telah berupaya untuk menjaga kualitas layanan situs website (electronic service quality).

Tabel 2: Agenda Pembaharuan Rutin Situs Website Aston Denpasar Hotel \& Convention Center Tahun 2017-2019

[Sumber: Departemen Sales \& Marketing Aston Denpasar Hotel \& Convention Center]

\begin{tabular}{ccc}
\hline No. & Jenis Pembaharuan & Waktu \\
\hline 1 & Harga Kamar & Setiap Hari \\
2 & Foto & Januari dan Juni \\
3 & Menu What's New & Disesuaikan \\
4 & Menu Special Offers & Disesuaikan \\
5 & Menu Guest Reviews & Disesuaikan \\
6 & Sistem keamanan & Disesuaikan \\
\hline
\end{tabular}


Pengaruh Electronic Service Quality dan Electronic Word of Mouth terhadap Keputusan Pembelian Kamar

Maureen Audria, I Nyoman Sudiksa, Ida Ayu Kalpikawati

\begin{tabular}{lll}
\hline 7 & Menu Facilities \& Services & Disesuaikan
\end{tabular}

Upaya menjaga kualitas layanan melalui situs web yang telah dilakukan oleh pihak hotel berpengaruh terhadap jumlah kunjungan dan durasi kunjungan tamu pada situs website Aston Denpasar Hotel \& Convention Center. Tabel 3 menunjukkan data jumlah dan durasi kunjungan pada situs website Aston Denpasar Hotel \& Convention Center.

Tabel 3: Jumlah \& Durasi Kunjungan Situs Website Aston Denpasar Hotel \& Convention Center Tahun 2017-2019

[Sumber: Departemen Sales \& Marketing Aston Denpasar Hotel \& Convention Center]

\begin{tabular}{ccc}
\hline Tahun & Jumlah Kunjungan & Rata-rata Durasi Kunjungan \\
\hline 2017 & 35.208 & 1 Menit 34 Detik \\
2018 & 35.598 & 1 Menit 47 Detik \\
2019 & 36.222 & 1 Menit 53 Detik \\
\hline
\end{tabular}

Berdasarkan data Tabel 3 terlihat bahwa terjadi peningkatan jumlah kunjungan situs website dari Tahun 2017-2019. Hal tersebut dapat diartikan bahwa semakin banyak orang yang melakukan pencarian informasi mengenai Aston Denpasar Hotel \& Convention Center melalui situs website. Durasi kunjungan situs website mengalami peningkatan dari Tahun 2017 hingga 2019. Peningkatan ini dapat diartikan bahwa semakin lama durasi kunjungan tamu untuk mencari informasi hotel pada situs website tersebut.

Terkait dengan ulasan online pihak Aston Denpasar Hotel \& Convention tidak melakukan pendataan khusus. Ulasan online dapat ditelusuri pada beberapa situs pihak ketiga yang bekerja sama dengan pihak Aston Denpasar Hotel \& Convention Center. Pada Tabel 4 dapat dilihat data ulasan online tamu terhadap kualitas layanan Aston Denpasar Hotel \& Convention Center dari berbagai media ulasan.

Berdasarkan data Tabel 4 menunjukkan bahwa lebih banyak tamu yang memiliki pengalaman baik selama menginap di Aston Denpasar Hotel \& Convention Center. Total ulasan positif dari tamu pada berbagai media memiliki jumlah lebih banyak dibandingkan ulasan negatif. Menurut Danish, dkk. (2019) ulasan online merupakan bagian yang sangat penting bagi perusahaan. Ulasan positif akan menghasilkan sikap positif untuk melakukan keputusan pembelian, sedangkan ulasan negatif akan memberikan pengaruh negatif terhadap perilaku pembelian konsumen.

Tabel 4: Ulasan Online Tamu Terhadap Aston Denpasar Hotel \& Convention Center Tahun 2009-2019

[Sumber: www.google.com, www.traveloka.com, www.agoda.com, www.tripadvisor.co.id, diakses pada 8 Maret 2020]

\begin{tabular}{ccccc}
\hline Media Ulasan & Total Ulasan & Ulasan Negatif & Ulasan Netral & Ulasan Positif \\
\hline Google Review & 3.707 & 185 & 445 & 3.077 \\
Traveloka & 1.796 & 4 & 266 & 1526 \\
Agoda & 412 & 103 & - & 309 \\
Trip Advisor & 376 & 49 & 95 & 232 \\
\hline
\end{tabular}

Pihak Aston Denpasar Hotel \& Convention Center telah melakukan upaya dalam pemasaran digital melalui electronic service quality dan electronic word of mouth, namun total pendapatan kamar yang diperoleh pada periode 2017-2019 mengalami penurunan. Pada Tabel 5 dapat dilihat data pendapatan kamar Aston Denpasar Hotel \& Convention Center dari Tahun 2017-2019. 
Pengaruh Electronic Service Quality dan Electronic Word of Mouth terhadap Keputusan Pembelian Kamar

Maureen Audria, I Nyoman Sudiksa, Ida Ayu Kalpikawati

Tabel 5: Jumlah Kamar Terjual \& Pendapatan Kamar Aston Denpasar Hotel \& Convention Center Tahun 2017-2019

[Sumber: General Manager Report 2017-2019 Aston Denpasar Hotel \& Convention Center]

\begin{tabular}{ccc}
\hline Tahun & Kamar Terjual & Total Pendapatan Kamar (Rp.) \\
\hline 2017 & 55.076 & 16.400 .531 .280 \\
2018 & 52.542 & 16.229 .750 .922 \\
2019 & 50.606 & 15.985 .271 .462 \\
Rata-rata & 52.741 & 16.205 .184 .555 \\
\hline
\end{tabular}

Berdasarkan Tabel 5 dapat dilihat bahwa pada Tahun 2017 jumlah kamar terjual mencapai 55.076 kamar dengan total pendapatan yaitu Rp. 16.400.531.280. Pada Tahun 2018, terjadi penurunan jumlah kamar terjual dan pendapatan kamar. Kamar terjual sebanyak 52.542 kamar, dengan pendapatan kamar sebesar Rp. 16.229.750.922. Kemudian pada Tahun 2019 terjadi penurunan kembali dengan jumlah kamar terjual sebanyak 50.606 kamar dengan pendapatan kamar sebesar Rp. 15.985.271.462. Hal tersebut menunjukkan bahwa meskipun pihak Aston Denpasar Hotel \& Convention Center telah melakukan pemasaran digital melalui electronic service quality dan electronic word of mouth, akan tetapi total pendapatan kamar yang diperoleh selama periode Tahun 20172019 mengalami penurunan.

Fenomena yang terjadi berdasarkan data yang telah dipaparkan adalah Aston Denpasar Hotel \& Convention Center telah melakukan upaya-upaya dalam menjaga kualitas layanan situs website serta telah memperoleh hasil positif dengan meningkatnya jumlah kunjungan dan durasi kunjungan situs website selama periode 2017-2019. Selain itu terdapat ulasan online positif dengan jumlah lebih banyak dari tamu yang pernah menginap di Aston Denpasar Hotel \& Convention Center. Namun total pendapatan kamar yang diperoleh pihak Aston Denpasar Hotel \& Convention Center selama periode 20172019 mengalami penurunan. Berdasarkan fenomena tersebut maka dilakukan penelitian ini dengan tujuan untuk menganalisis pengaruh electronic service quality dan electronic word of mouth terhadap keputusan pembelian kamar di Aston Denpasar Hotel \& Convention Center secara parsial dan simultan.

\section{METODE PENELITIAN}

Data penelitian ini diperoleh dengan penyebaran kuesioner online (dengan bantuan Google Form) dan studi dokumentasi. Populasi responden pada penelitian ini adalah tamu yang pernah menginap di Aston Denpasar Hotel \& Convention Center dari Tahun 20172019. Pengambilan sampel dilakukan dengan menggunakan rumus slovin (tingkat error 10\%) sehingga memperoleh 100 sampel responden. Data yang diperoleh adalah data primer dari hasil penyebaran kuesioner online dan dilakukan analisis data dengan uji asumsi klasik, uji regresi linier berganda, uji t, uji F, analisis koefisien determinasi dan sumbangan efektif. Selain itu penelitian ini menggunakan data sekunder berupa dokumen yang diberikan oleh pihak Aston Denpasar Hotel \& Convention Center. Penelitian ini memiliki model penelitian sebagai berikut: 
Maureen Audria, I Nyoman Sudiksa, Ida Ayu Kalpikawati

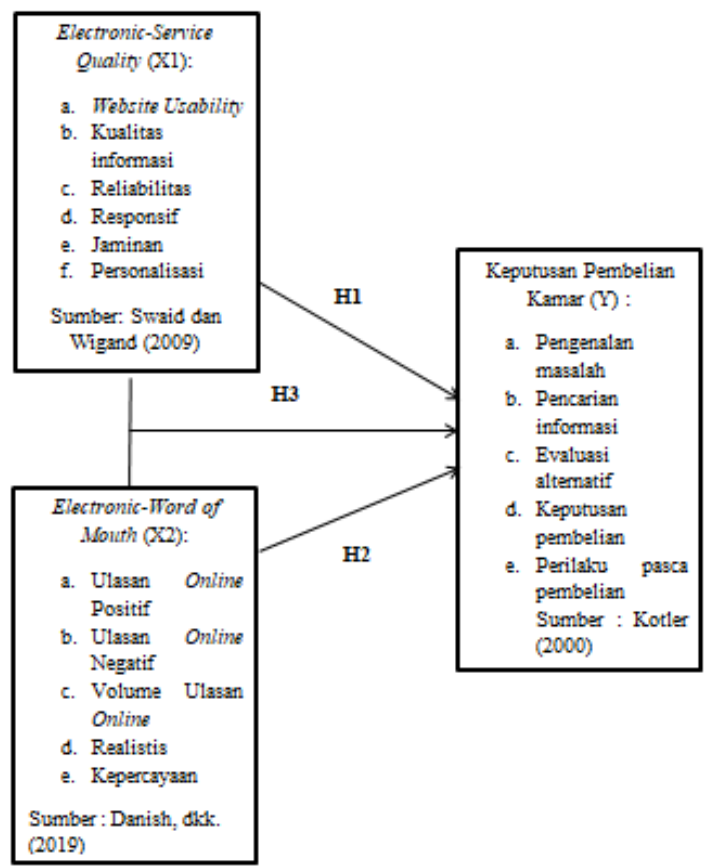

Gambar 1. Model Penelitian

[Sumber: Swaid dan Wigand (2009), Danish, dkk. (2019) dan Kotler (2000)]

Pada Gambar 1 dapat dilihat bahwa terdapat 2 variabel independen yaitu electronic service quality dan electronic word of mouth serta 1 variabel dependen yaitu keputusan pembelian kamar. Variabel electronic service quality terdiri atas 6 atribut yaitu website usability, kualitas informasi, reliabilitas, responsif, jaminan dan personalisasi. Variabel electronic word of mouth terdiri atas 5 atribut yaitu ulasan online positif, ulasan online negatif, volume ulasan online, realistis dan kepercayaan. Variabel keputusan pembelian terdiri atas 5 atribut yaitu pengenalan masalah, pencarian informasi, evaluasi alternatif, keputusan pembelian dan perilaku pasca pembelian. Penelitian ini akan dilakukan untuk mengetahui pengaruh variabel electronic service quality dan electronic word of mouth terhadap keputusan pembelian kamar secara parsial dan simultan.

Berdasarkan metode penelitian dan landasan teori tentang pengaruh electronicservice quality dan electronic-word of mouth terhadap keputusan pembelian kamar, hipotesis pada penelitian ini dapat dirumuskan sebagai berikut.

H01: electronic-service quality tidak berpengaruh signifikan terhadap keputusan pembelian kamar di Aston Denpasar Hotel \& Convention Center.

Ha1: electronic-service quality berpengaruh signifikan terhadap keputusan pembelian kamar di Aston Denpasar Hotel \& Convention Center.

H02: electronic-word of mouth tidak berpengaruh signifikan terhadap keputusan pembelian kamar di Aston Denpasar Hotel \& Convention Center.

Ha2: electronic-word of mouth berpengaruh signifikan terhadap keputusan pembelian kamar di Aston Denpasar Hotel \& Convention Center.

H03: electronic-service quality dan electronic-word of mouth tidak berpengaruh signifikan terhadap keputusan pembelian kamar di Aston Denpasar Hotel \& Convention Center.

Ha3: electronic-service quality dan electronic-word of mouth berpengaruh signifikan terhadap keputusan pembelian kamar di Aston Denpasar Hotel \& Convention Center. 


\section{HASIL DAN PEMBAHASAN}

Karakteristik responden adalah sebagai berikut: (1) Responden laki laki sebesar 54\% dan perempuan sebesar 46\%; (2) Usia responden dominan berusia 31-40 tahun sebesar 51\%; (3) Pendidikan didominasi oleh sarjana sebesar 43\%; dan (4) Status pekerjaan sebagai karyawan swasta sebesar $47 \%$.

Uji Asumsi klasik pada penelitian ini menunjukkan bahwa regresi berdistribusi normal dengan nilai Kolmogorov-Smirnov (K-S) sebesar 0,073 dan nilai Asymp Sig (2tailed) sebesar 0,200. Nilai tolerance dan Variance Inflation Factor (VIF) dari variabel electronic service quality dan electronic word of mouth menunjukkan nilai tolerance untuk setiap variabel lebih besar dari $10 \%$ dan nilai VIF lebih kecil dari 10 yang berarti model persamaan regresi bebas dari multikolinearitas. Nilai signifikansi dari variabel electronic service quality sebesar 0,370 dan nilai signifikansi dari variabel electronic word of mouth sebesar 0,914. Nilai tersebut lebih besar dari 0,10 yang berarti tidak terdapat pengaruh antara variabel bebas terhadap absolute residual. Dengan demikian, model yang dibuat tidak mengandung gejala heteroskedastisitas. berikut:

Dari hasil analisis regresi linier berganda dapat disusun persamaan regresi sebagai

$$
\begin{aligned}
& \text { KPK }=18,086+0,199 \text { E-SQ }+0,330 \text { E-WOM } \\
& \text { Keterangan : } \\
& \begin{array}{ll}
\text { KPK } & =\text { Keputusan Pembelian Kamar } \\
\text { E-SQ } & =\text { Electronic-Service Quality } \\
\text { E-WOM } & =\text { Electronic-word of mouth }
\end{array}
\end{aligned}
$$

Nilai konstanta sebesar 18,086 artinya apabila electronic service quality dan electronic word of mouth ditiadakan maka keputusan pembelian kamar bernilai sebesar 18,086. Nilai koefisien regresi variabel electronic service quality terhadap keputusan pembelian kamar sebesar 0,199 artinya apabila electronic service quality mengalami kenaikan satu satuan, sementara variabel lainnya tetap maka keputusan pembelian kamar akan mengalami peningkatan sebesar 0,199. Nilai koefisien regresi variabel electronic word of mouth terhadap keputusan pembelian kamar sebesar 0,330 artinya apabila electronic word of mouth mengalami kenaikan satu satuan, sementara variabel lainnya tetap maka keputusan pembelian kamar akan mengalami peningkatan sebesar 0,330.

Hasil uji t menunjukkan bahwa nilai thitung $>$ ttabel $=(2,579>1,985)$ dan $p$ value $<a$ $(0,011<0,1)$ maka H01 ditolak dan Ha1 diterima. Hal tersebut berarti bahwa secara statistika pada taraf kepercayaan (a) 0,1 electronic service quality berpengaruh positif dan signifikan terhadap keputusan pembelian kamar. Hasil uji t menunjukkan bahwa nilai thitung $>$ ttabel $=(2,646>1,985)$ dan $\mathrm{p}$ value $<\mathrm{a}(0,010<0,1)$ maka H02 ditolak dan Ha2 diterima. Hal tersebut berarti bahwa secara statistika pada taraf kepercayaan (a) 0,1 electronic word of mouth berpengaruh positif dan signifikan terhadap keputusan pembelian kamar.

Berdasarkan nilai Fhitung yang diperoleh dengan menggunakan program SPSS 22.0 for Windows didapatkan hasil sebesar 11,641. Dapat dijelaskan apabila nilai $\mathrm{F}_{\text {hitung }}=$ 11,641 lebih besar dari $\mathrm{F}_{\text {tabel }}=2,36$ maka Fhitung berada pada daerah penolakan $\mathrm{H}_{0} 3$, dengan demikian $\mathrm{H}_{0} 3$ ditolak dan $\mathrm{Ha} 3$ diterima. Hal ini berarti bahwa secara statistik uji bersama-sama electronic service quality dan electronic word of mouth dengan uji satu sisi dan taraf kepercayaan $(a)=10 \%$, berpengaruh positif terhadap keputusan pembelian kamar di Aston Denpasar Hotel \& Convention Center.

Pengaruh electronic service quality dan electronic word of mouth terhadap keputusan pembelian kamar di Aston Denpasar Hotel \& Convention Center adalah sebesar 46,6\% yang dapat diartikan variabel electronic service quality dan electronic word of mouth mempunyai pengaruh yang sedang terhadap keputusan pembelian kamar di Aston 
Denpasar Hotel \& Convention Center karena berada pada interval koefisien determinasi $40 \%$ - 59,9\%, sedangkan sisanya 53,4 \% dipengaruhi oleh faktor lain yang ddalam penelitian ini tidak diteliti. pengaruh electronic service quality terhadap keputusan pembelian kamar secara parsial sebesar 22\%. Pengaruh electronic word of mouth terhadap keputusan pembelian kamar secara parsial sebesar 24,6\%.

Persamaan penelitian ini dengan penelitian terdahulu yang dilakukan oleh Baeshen, dkk (2017) adalah pada atribut electronic service quality yang digunakan yaitu kemudahan dalam penggunaan situs web, kualitas informasi, reliabilitas, responsif dan jaminan. Hasil penelitian tersebut menunjukkan bahwa situs web saluran distribusi online memberikan pengaruh positif terhadap keputusan pembelian secara parsial dan simultan dengan variabel mediasi yaitu Ewom. Namun pada penelitian ini, menunjukkan hasil bahwa situs web hotel secara langsung memberikan pengaruh positif dan signifikan terhadap keputusan pembelian. Berdasarkan hal tersebut, hotel perlu meningkatkan kualitas situs web sehingga meningkatkan minat tamu untuk melakukan keputusan pembelian kamar secara langsung melalui situs web hotel tanpa melalui saluran distribusi online.

Persamaan penelitian ini dengan penelitian terdahulu yang dilakukan oleh AbdElaziz, dkk (2015) adalah pada atribut electronic word of mouth yang digunakan yaitu volume ulasan, realistis dan kepercayaan. Hasil penelitian tersebut menunjukkan bahwa jumlah volume ulasan mungkin dapat meningkatkan minat tamu untuk melakukan keputusan pembelian. Namun dalam penelitian ini ditemukan bahwa jumlah volume ulasan online memiliki nilai terendah dalam mempengaruhi konsumen memilih hotel. Berdasarkan hal tersebut, pihak hotel perlu lebih memperhatikan isi konten pada ulasan yang diberikan oleh tamu dibandingkan jumlah ulasan yang diberikan.

\section{KESIMPULAN}

Kesimpulan penelitian ini adalah electronic service quality memberikan pengaruh positif dan signifikan terhadap keputusan pembelian kamar di Aston Denpasar Hotel \& Convention Center. Jika electronic service quality semakin meningkat maka akan meningkatkan pula keputusan pembelian kamar di Aston Denpasar Hotel \& Convention Center. Electronic word of mouth memberikan pengaruh positif dan signifikan terhadap keputusan pembelian kamar di Aston Denpasar Hotel \& Convention Center. Jika electronic word of mouth semakin meningkat maka akan meningkatkan pula keputusan pembelian kamar di Aston Denpasar Hotel \& Convention Center. Electronic service quality dan electronic word of mouth memberikan pengaruh yang positif dan signifikan secara simultan terhadap keputusan pembelian kamar di Aston Denpasar Hotel \& Convention Center. Jika electronic service quality dan electronic word of mouth semakin meningkat maka semakin meningkat pula keputusan pembelian kamar di Aston Denpasar Hotel \& Convention Center. Pengaruh variabel electronic service quality dan electronic word of mouth terhadap keputusan pembelian kamar sebesar 46,6\%, dengan sumbangan efektif variabel electronic service quality terhadap keputusan pembelian kamar di Aston Denpasar Hotel \& Convention Center secara parsial sebesar 22\%. Sementara sumbangan efektif variabel electronic word of mouth terhadap keputusan pembelian kamar di Aston Denpasar Hotel \& Convention Center secara parsial sebesar 24,6\%.

Pada penelitian ini ditemukan bahwa manajemen Aston Denpasar Hotel \& Convention Center perlu melakukan peningkatan pada electronic service quality dan electronic word of mouth dengan memperhatikan fitur bantuan bagi tamu yang mengakses situs website hotel. Bantuan yang dimaksud dapat melalui live chat untuk mempermudah pihak yang mengakses situs website hotel. Terkait electronic word of mouth, hal yang dapat dilakukan dengan pengunggahan kembali (repost) ulasan online tamu yang menyatakan puas terhadap produk dan layanan Aston Denpasar Hotel \& Convention 
Center. Pihak manajemen juga perlu memberikan apresiasi berupa respon kepada tamu yang telah berkenan memberikan ulasan online.

\section{DAFTAR PUSTAKA}

Abd-Elaziz, M.E., Aziz, W. M., Khalifa, G. S. A., \& Ma'youf, M. A. A. (2015). Determinants of Electronic Word of Mouth (Ewom) Influence on Hotel Customers' Purchase Decision. Journal of Faculty of Tourism and Hotels Fayoum University. 9 (2/2) Diakses dari https://www.researchgate.net/publication/295551680_Determinants_of_Electronic _word_of_mouth_EWOM_influence_on_hotel_customers\%27_purchasing_decision.

Baeshen, Y., Al-Karaghouli, W., \& Ghoneim, A. (2017). Investigating The Effect Of Website Quality on Ewom and Customer Purchase Decision: Third Parties Hotel Websites. IML'17 Proceedings of the 1st International Conference on Internet of Things and Machine Learning. Diakses dari https://doi.org/10.1145/3109761.3109766.

Danish, R. Q., Hafeez, S., Ali, H. F., Shahid, R., \& Nadeem, K. (2019). Impact of Online Consumer Reviews on Hotel Booking Intentions: The Case of Pakistan. European $\begin{array}{lllll}\text { Scientific } & \text { Journal. } & 15 & \text { (7) } & \text { Diakses }\end{array}$ https://doi.org/10.19044/esj.2019.v15n7p144.

Desai, V. (2019). Digital Marketing: a Review. International Journal of Trend in Scientific Research and Development. doi: 10.31142/ijtsrd23100.

Hutapea, J. Y. (2016). The Evolution on Marketing Concept: Analysis on The Perspective Changes in Marketing Concept. Universitas Advent Indonesia. Diakses dari https://jurnal.unai.edu/index.php/jiscbg/article/view/393.

Jalilvand, M. R., Eshafani, S. S., \& Samici, N. (2010). Electronic Word-of Mouth: Challenges and Oppportunities. World Conferences on International Telecommunications 2010. doi: https://doi.org/10.1016/j.procs.2010.12.008.

Jenny Kim, J., Lee, Y. \& Han, H. (2019). Exploring Competitive Hotel Selection Atributes Among Guests: An Importance-Perfomance Analysis. Journal of Travel \& Tourism Marketing. doi: 10.1080/10548408.2019.1683484.

Kazandzhieva, V., Ilieva, G., \& Filipova, H. (2017). The Impact of Technological Innovations on Hospitality Service. Contemporary Tourism-Traditions and Innovations, Sofia University. Diakses dari https://www.researchgate.net/publication/317290270

Knutson, B. J. (1988). Frequent Travelers: Making Them Happy and Bringing Them Back. The Cornell Hotel Restaurant Administration Quarterly. doi: https://doi.org/10.1177/001088048802900121.

Kotler, P. (2000). Prinsip-Prinsip Pemasaran Manajemen. Jakarta: Prehalindo.

Kotler, P., Keller, K. L. (2007). Manajemen Pemasaran Jilid 12. Jakarta: PT. Indeks.

Pandora M. Inc. (2017). Membership Interest Purchase Agreement. Pandora Media Inc. Diakses dari https://www.lawinsider.com/contracts/208vimPW9MlEbokDaV0pIv /2018-08-23.

Shared, H. A. (2019). The Relationship between E-Service Quality and E-Customer Satisfaction: An Empirical Study in Egyptian Banks. International Journal of Business and Management. Diakses dari doi:10.5539/ijbm.v14n5p171.

Swaid, S. I., \& Wigand, R.T. (2009). Measuring The Quality of E-Service: Scale Development and Initial Validation. Journal of Electronic Commerce Research. Diakses dari https://www.researchgate.net/publication/228623561_Measuring_the_quality_of_E -service_Scale_development_and_initial_validation.

Zhang, X., \& Tang, Y. (2006). Customer Perceived E-Service Quality in Online Shopping. (Master Thesis, Lulea University of Technology). Diakses dari https://www.divaportal.org/smash/get/diva2:1026712/FULLTEXT01.pdf. 